\title{
FPD2GB2: Automating a transition from a customized genome browser to GBrowse2
}

\author{
Roger Chui ${ }^{* *}$, Jerzy W Jaromczyk ${ }^{1}$, Neil Moore ${ }^{1}$, Christopher L Schardl ${ }^{2}$ \\ From 12th Annual UT-ORNL-KBRIN Bioinformatics Summit 2013 \\ Buchanan, TN, USA. 22-24 March 2013
}

\section{Background}

We present FPD2GB2, a collection of scripts to automate data migration of a custom genome database and browser to a new implementation. The fungal endophytes genome project (http://www.endophyte.uky.edu/) hosted at the University of Kentucky uses a custom genome browser and database to support several genome sequencing, annotation, and analysis projects. This system is currently based around a locally-developed genome annotation database, visualized using the GBrowse version 1 genome browser together with a large amount of custom code that supports metadata and rendering features not supported by GBrowse 1. Since our initial development of our genome site, a newer version of GBrowse, version 2, has been released. Unlike GBrowse version 1, version 2 supports a very expressive database schema based on the standardized GFF3 format. This schema natively supports the types of data that we currently store in our custom database. In order to simplify maintenance, to ease the upgrade path to future versions of GBrowse, and to improve interoperability with software and websites that support GBrowse and the GFF3 format, we have decided to migrate our custom database to the GFF3 format supported by GBrowse 2 . This migration allows us to simplify and in some cases even eliminate much of our custom code. We discuss the challenges presented by such a data migration task, and describe the FPD2GB2 script collection we developed to automate the process.

\section{Acknowledgements}

This work was partially supported by NIGMS Grant 1R01GM086888-01, Kentucky NSF-EPSCoR Grant 0814194, NSF Grant EF-0523661, and USDA-NRA Grant 2005-35319-16141.

${ }^{1}$ Department of Computer Science, University of Kentucky, Lexington, $\mathrm{KY}$ 40506, USA

Full list of author information is available at the end of the article
Authors' details

'Department of Computer Science, University of Kentucky, Lexington, KY 40506, USA. ²Department of Plant Pathology, University of Kentucky, Lexington, KY 40546, USA.

Published: 22 October 2013

doi:10.1186/1471-2105-14-S17-A17

Cite this article as: Chui et al: FPD2GB2: Automating a transition from a customized genome browser to GBrowse2. BMC Bioinformatics 2013 14(Suppl 17):A17.
Submit your next manuscript to BioMed Central and take full advantage of:

- Convenient online submission

- Thorough peer review

- No space constraints or color figure charges

- Immediate publication on acceptance

- Inclusion in PubMed, CAS, Scopus and Google Scholar

- Research which is freely available for redistribution
C Biomed Central
C Biomed Central

(c) 2013 Chui et al; licensee BioMed Central Ltd. This is an Open Access article distributed under the terms of the Creative Commons Attribution License (http://creativecommons.org/licenses/by/2.0), which permits unrestricted use, distribution, and reproduction in any medium, provided the original work is properly cited. 